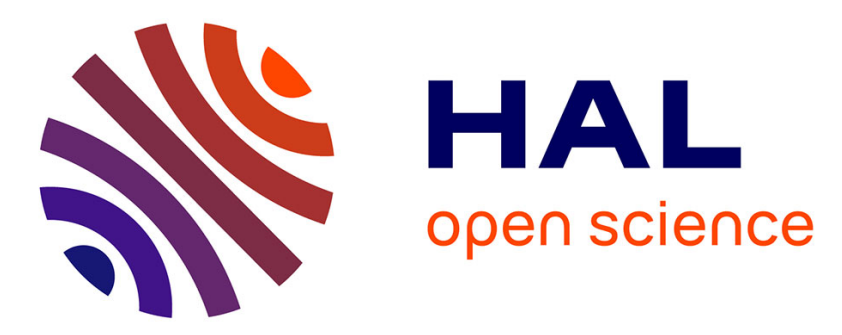

\title{
Identification and characterisation of FUS/TLS as a new target of ATM
}

Mary Gardiner, Rachel Toth, Franck Vandermoere, Nicholas A Morrice, John

Rouse

\section{To cite this version:}

Mary Gardiner, Rachel Toth, Franck Vandermoere, Nicholas A Morrice, John Rouse. Identification and characterisation of FUS/TLS as a new target of ATM. Biochemical Journal, 2008, 415 (2), pp.297307. 10.1042/BJ20081135 . hal-00479035

\section{HAL Id: hal-00479035 https://hal.science/hal-00479035}

Submitted on 30 Apr 2010

HAL is a multi-disciplinary open access archive for the deposit and dissemination of scientific research documents, whether they are published or not. The documents may come from teaching and research institutions in France or abroad, or from public or private research centers.
L'archive ouverte pluridisciplinaire HAL, est destinée au dépôt et à la diffusion de documents scientifiques de niveau recherche, publiés ou non, émanant des établissements d'enseignement et de recherche français ou étrangers, des laboratoires publics ou privés. 
Identification and characterisation of FUS/TLS as a new target of ATM

Mary Gardiner, Rachel Toth, Franck Vandermoere, Nicholas A. Morrice \& John Rouse ${ }^{1}$

MRC Protein Phosphorylation Unit, Sir James Black Centre, University of Dundee, Dundee DD1 5EH, UK.

Running title: FUS/TLS and ATM

${ }^{1}$ To whom correspondence should be addressed

keywords: kinase; DNA damage; FUS; ATM; phosphorylation; EWS

e-mail: j.rouse@dundee.ac.uk

tel: $\quad+44-1382-385490$

fax: $+44-1382-223778$ 
ATM, ATR and DNA-PK, important regulators of genome stability, belong to the PI(3)-kinase-like kinase (PIKK) family of protein kinases. In this study, DNA affinity chromatography was used to identify DNA binding proteins phosphorylated by these kinases. This resulted in the identification of FUS/TLS as an in vitro target of the PIKK kinases. FUS is a member of the Ewing's sarcoma family of proteins, and that appear to play a role in regulating genome stability since mice lacking FUS show chromosomal instability and defects in meiosis. The residues in FUS that are phosphorylated in vitro and in vivo were identified and phospho-specific antibodies were generated to demonstrate that FUS becomes phosphorylated at Ser42 in vivo primarily in response to agents that cause double-strand breaks (DSBs). DSB-induced FUS phosphorylation in vivo at Ser42 requires ATM and not DNA-PK. Although Ser42 is retained in the oncogenic FUSCHOP fusion caused by a $\mathrm{t}(12 ; 16)(\mathrm{q} 13 ; \mathrm{p} 11)$ chromosomal translocation, Ser42 in FUS-CHOP is not phosphorylated after DNA damage. These results identify FUS as a new target of the ATM signalling pathway and strengthen the notion that FUS regulates genome stability. 


\section{Introduction}

ATM (ataxia-telangiectasia mutated), ATR (서 $\underline{\text { ATM }}$ and3-related) and DNAdependent protein kinase (DNA-PK) are key regulators of cellular responses to DNA-damage [1]. They belong to a conserved family of protein kinases termed the phosphatidyl inositol 3-kinase-like kinases (PIKKs) because the catalytic domains of these proteins show similarity to PI(3)-kinase [2]. ATM and DNA-PK respond to double-strand breaks while ATR responds to almost all types of DNA damage as well as to perturbations during DNA replication [3].These kinases are recruited to ss 
binding domain of the transcription factor CHOP in human myxoid and round cell liposarcomas as a consequence of a $\mathrm{t}(12 ; 16)(\mathrm{q} 13 ; \mathrm{p} 11)$ translocation $[22,23]$. This results in the expression of a FUS-CHOP fusion protein that is sufficient for cell transformation, and this requires the FUS portion of the oncogenic fusion protein $[24,25]$. It was subsequently shown that FUS and its two close relatives, EWS (Ewing's sarcoma) and TAF15/TAFII68, are fused to a variety of transcription factors, resulting in the expression of transforming oncoproteins in various human sarcomas and leukemias [26]. The normal cellular functions of wild-type FUS (or EWS or TAF15) are unknown. These proteins have features typical of RNAbinding proteins, including a highly conserved RNA recognition motif (RRM) flanked by Arg-Gly-Gly (RGG) repeats [27, 28]. FUS has been shown to bind RNA in vitro and in vivo $[22,29]$ but the relevance of these observations to FUS function are unknown. FUS also has a zinc finger motif and may bind to DNA [30]. A variety of cellular interactors have been reported for FUS including hnRNPs, splicing factors and transcription factors [29, 31, 32].

FUS-deficient mice show increased sensitivity to ionizing radiation, meiotic defects resulting in male sterility and high levels of chromosomal abnormalities $[20,33]$. Intriguingly, FUS has been shown to be able to stimulate the formation of DNA "D-loops" between complementary DNAs in vitro [34]. This type of DNA transaction corresponds to one of the first steps in homologous recombination, "strand invasion". Taken together these data suggest FUS might play a role in the cellular response to DNA damage and the ability of FUS to stimulate D-loop formation has led to speculation about a role for FUS in HR [35].

We identified FUS in a screen for DNA binding proteins that are phosphorylated in vitro by members of the PIKK family of kinases. Exposure of cells to agents that induce DSBs, such as ionizing radiation and the topoisomerase II inhibitor etoposide, caused FUS to become phosphorylated in vivo. The sites of FUS phosphorylation were identified and phospho-specific antibodies were used to demonstrate that FUS is a target of ATM in vivo when double-strand breaks arise. Intriguingly, although Ser42 is retained in the oncogenic FUS-CHOP fusion caused by a $\mathrm{t}(12 ; 16)(\mathrm{q} 13 ; \mathrm{p} 11)$ chromosomal translocation, Ser42 in FUS-CHOP is not phosphorylated after DNA damage. These results in show clearly that FUS is a novel target of the ATM signalling pathway.

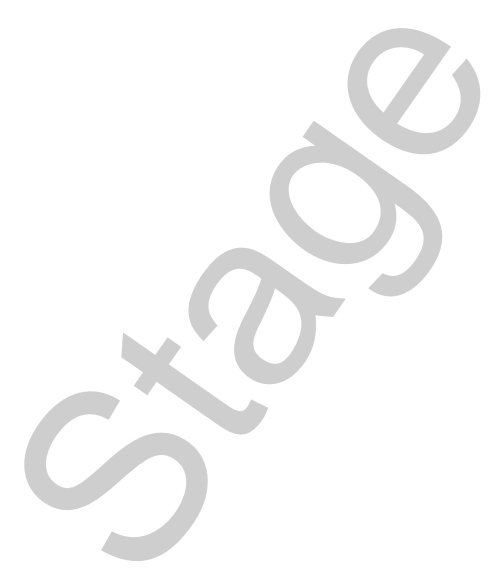




\section{Materials and Methods}

\section{Cell lines and treatments}

HEK 293 cells were grown in Dulbecco's Modified Eagles Medium (DMEM) (GIBCO) supplemented with 10\% foetal bovine serum (FBS, HyClone; 293 cells) and $10 \%$ heat inactivated FBS (GIBCO; MEFs). Growth media also contained 1\% penicillin/streptomycin and 1\% L-glutamate (both from Invitrogen). All cells were maintained at $37^{\circ} \mathrm{C}$ in a humidified atmosphere containing $5 \% \mathrm{CO}_{2}$. The ATM inhibitor KU55933 and the DNA-PK inhibitor NU7441, prepared at stock concentrations of $10 \mathrm{mM}$ in DMSO, were kindly provided by Dr Graeme Smith (KuDOS Pharmaceuticals, Cambridge, UK) [36, 37]. To induce DNA damage, exponentially growing cells that were treated, or not, with KU55933, NU7441 or with empty vehicle (DMSO) for $1 \mathrm{hr}$, were exposed to the indicated doses of IR, delivered from a $\mathrm{Cs}^{137}$ source at a dose rate of 2.9 Gy per minute, or were incubated with etoposide $(10 \mu \mathrm{M})$, MMS $(0.01 \%)$, HU $(10 \mathrm{mM})$. Samples were taken immediately prior to and at different times after treatment. For western blot analysis and immunoprecipitation cells were lysed in native lysis buffer: $50 \mathrm{mM}$ Tris ( $\mathrm{pH} 7.4$ ), $0.27 \mathrm{M}$ sucrose, $1 \%$ Triton $\mathrm{X}-100,1 \mu \mathrm{M}$ microcystin-LR and protease inhibitors. Lysates for immunoprecipitations were snap-frozen and stored at $-80^{\circ} \mathrm{C}$ till required. For western blotting, lysates were denatured in lithium dodecyl sulphate (LDS) sample buffer (Invitrogen) containing 2-mercaptoethanol (10\% (v/v)). Proteins were separated by electrophoresis using $4-12 \%$ Bis-Tris gels (Invitrogen), transferred to nitrocellulose and subjected to western blotting with the indicated antibody.

\section{Antibodies and plasmids}

The primary antibodies used in this study were: anti-FUS, anti-SMC1 phosphoSer966 and anti-SMC1 (Axxora), anti-GADD153 (CHOP) (Santa Cruz Biotechnology), anti-HA (12CA5, Roche), anti-FLAG (Sigma) and anti-MUS81 (Abcam). A phosphospecific antibody against Ser42 of FUS was raised by immunizing sheep with the following peptide coupled to KLH (keyhole limpet hemocyanin): QQSYSGYpSQSTDTSG where $\mathrm{pS}$ represents phospho-Ser42. The antibody was purified from sheep serum by affinity chromatography on $\mathrm{CH}$ Sepharose to which the phosphopeptide immunogen had been coupled covalently. Immunoblots with this antibody were performed in the presence of $40 \mu \mathrm{g} / \mathrm{ml} \mathrm{non-}$ phosphopeptide to neutralize any antibodies that recognized the unphosphorylated FUS. HRP-conjugated secondary antibodies were obtained from Pierce and were used at a dilution of 1:4000 for $1 \mathrm{hr}$. Full-length FUS was amplified with an N-terminal HA tag, sub-cloned into pCR2.1 and cloned into the NotI and BamHI sites of pCMV5. FUS was also cloned into pGEX-6P1 from pCR2.1, again using NotI and BamHI. FUS-CHOP was amplified with an N-terminal FLAG tag from a bluescript vector (a kind gift from Terence Rabbitts) and cloned into the BamH1 and Xho1 sites of pcDNA3. Mutations were introduced into pCMV-HA-FUS using the Quikchange Multi-Site mutagenesis kit (Stratagene). Plasmids were transfected into HEK293 cells using a calcium phosphate precipitation method.

\section{DNA affinity chromatography}

Linear double-stranded (ds) DNA, Holliday junction and "Y-fork" structures were made by annealing the following oligonucleotides: 888, 889890 and 891 (Holliday junction), 888 and 891 (Y-fork), P1 and P2 for dsDNA. P1 was used for single-strand DNA. 888, 889, 890, 891 are described in [38], and the sequences of P1 and P2 are shown below. 888 and P1 were synthesised with a 5' biotin moiety, and all the bases 
in each oligonucleotide were phosphorothiorate-substituted. Oligonucleotides were from Sigma-Genosys and were HPLC-purified. To make each structure, $100 \mu \mathrm{g}$ of the relevant oligonucleotides were incubated in $100 \mu \mathrm{l}$ of annealing buffer $(50 \mathrm{mM}$ Tris $\mathrm{pH}$ 7.6, $10 \mathrm{mM} \mathrm{MgCl}_{2}, 0.1 \mathrm{mM}$ EDTA pH 8.0) and boiled at $95^{\circ} \mathrm{C}$ for $5 \mathrm{~min}$ before cooling at room temperature for a minimum of $2 \mathrm{hr}$. Streptavidin-coated Dynabeads (Dynal Biotech) $(300 \mu \mathrm{l})$ were washed three times in annealing buffer then added to the annealed oligonucleotides and the mixture was incubated at room temperature for $30 \mathrm{~min}$. The beads were then washed five times in annealing buffer and re-suspended in $300 \mu \mathrm{l}$ of this buffer and stored at $4^{\circ} \mathrm{C}$.

P1:TGCAACAACTTTTTTCGCTCCCGATAGTGAGTCGTATTTTTTAGCTGAG CCAGGTTTCCCCGATTTCCAGAC P2:GTCTGGAAATCGGGGAAACCTGGCTCAGCTAAAAAATACGACTCACTA TCGGGAGCGAAAAAAGTTGTTGCA

In small-scale chromatography experiments (Fig. 1A) $10 \mu \mathrm{l}$ of DNA beads were incubated with $300 \mu \mathrm{g}$ of HeLa whole cell extract and in large-scale experiments (Fig. 1B), $30 \mu \mathrm{l}$ beads were incubated with approximately $50 \mathrm{mg}$ of HeLa of whole cell extract. Incubations were for $1 \mathrm{hr}$ at $4^{\circ} \mathrm{C}$ followed by four washes in lysis buffer. Beads then subjected to phosphorylation reactions or were denatured in SDS sample buffer, heated at $95^{\circ} \mathrm{C}$ for $5 \mathrm{~min}$ and then subjected to SDS-PAGE followed by either Coomassie staining or western blot analysis.

\section{Stable transfection of HEK293 cells with FLAG-tagged FUS-CHOP fusion protein}

Early passage HEK293 cells were transfected with pcDNA3- FLAG FUS-CHOP using the calcium phosphate method [39]. After $16 \mathrm{hr}$ the transfected cells were seeded at $50 \%$ confluence and were allowed to adhere to dishes overnight before addition of G418 (3 mg/ml). After eight days, G418-resistant colonies were isolated and expanded. FLAG-FUS-CHOP expression was tested by western blotting.

\section{Identification of FUS residues phosphorylated by DNA-PK in vitro}

FUS was immunoprecipitated from $25 \mathrm{mg}$ of cell extract protein, for $90 \mathrm{~min}$ at $4^{\circ} \mathrm{C}$, with $5 \mu \mathrm{g}$ of anti-FUS antibody non-covalently bound to protein $\mathrm{G}-$ coated Dynabeads (Dynal Biotech). Beads were washed four times in ice-cold lysis buffer containing $0.5 \mathrm{M} \mathrm{NaCl}$ and once in buffer containing $0.15 \mathrm{M} \mathrm{NaCl}$ before phosphorylation of FUS to stoichiometry with DNA-PK in vitro for $60 \mathrm{~min}$ (see last section). After phosphorylation, samples were boiled in $15 \mu 1$ of 2X LDS sample buffer (Invitrogen) and subjected to electrophoresis on $4-12 \%(\mathrm{w} / \mathrm{v})$ polyacrylamide gels followed by fixation and staining with colloidal Coomassie Blue (Invitrogen). FUS, which was evident as a $66 \mathrm{kDa}$ band after staining, was excised and the amount of ${ }^{32} \mathrm{P}$ incorporated was determined by Cerenkov counting. For phospho-site mapping, the protein was reduced with dithiothreitol, alkylated with iodoacetamide and digested with chymotrypsin. The resulting peptides were applied to a Vydac 218TP215 C18 column equilibrated in $0.1 \%$ TFA and the column was developed with a linear gradient of acetonitrile $/ 0.1 \%$ TFA at a flow rate of $0.2 \mathrm{ml} / \mathrm{min}$ while collecting $0.1 \mathrm{ml}$ fractions. ${ }^{32} \mathrm{P}$ radioactivity was recorded with an online monitor. Phosphorylation site mapping was performed essentially as described previously [40]. Identification of ${ }^{32} \mathrm{P}$ labelled peptides was performed by MALDI-TOF (matrix-assisted laser-desorption ionization-time of flight) and MALDI-TOF-TOF MS on an Applied Biosystems 4700 using a matrix of $10 \mathrm{mg} / \mathrm{ml} \alpha$-cyanocinnamic acid in $50 \%$ acetonitrile $/ 0.1 \% \mathrm{TFA} / 10$ 
$\mathrm{mM}$ ammonium phosphate. Sites of phosphorylation within the peptides were determined by a combination of MALDI-TOF-TOF-MS and solid-phase Edman sequencing. Solid-phase sequencing was performed on an Applied Biosystems Procise 494C after coupling the peptide covalently with a Sequelonarylamine membrane and measuring the ${ }^{32} \mathrm{P}$ radioactivity released after each cycle by Cerenkov counting.

\section{Q-trap mass spectrometric identification of in vivo sites of FUS phosphorylation} HEK293 cells (15 x 10cm dishes per treatment) were exposed to IR (20 Gy), or not, and left to recover for $1 \mathrm{hr}$. Cells were lysed into ice-cold buffer containing $50 \mathrm{mM}$ Tris ( $\mathrm{pH} 7.4), 0.27 \mathrm{M}$ sucrose, $1 \%(\mathrm{w} / \mathrm{v})$ Triton $\mathrm{X}-100,1 \mu \mathrm{M}$ microcystin-LR including a cocktail of protease inhibitors and centrifuged for 5 minutes at 13000rpm at $4^{\circ} \mathrm{C}$. FUS was immunoprecipitated from $25 \mathrm{mg}$ of cell extract protein, for $90 \mathrm{~min}$ at $4^{\circ} \mathrm{C}$, with $5 \mu \mathrm{g}$ of anti-FUS antibody bound to protein G-Dynabeads (Dynal Biotech). Beads were washed four times in ice-cold lysis buffer containing $0.5 \mathrm{M} \mathrm{NaCl}$ and once in buffer containing $0.15 \mathrm{M} \mathrm{NaCl}$ before boiling in $15 \mu 12 \mathrm{X}$ LDS sample buffer (Invitrogen). Proteins were subjected to SDS-PAGE on 4-12\% Bis-Tris gels (Invitrogen) and stained with colloidal Coomassie Blue (Invitrogen). FUS bands were excised and digested in $50 \mathrm{mM}$ triethylammonium bicarbonate with chymotrypsin ( 5 $\mu \mathrm{g} / \mathrm{ml}$ ) (Promega) at $30^{\circ} \mathrm{C}$ for $18 \mathrm{hr}$. An equivalent volume of acetonitrile was added for $15 \mathrm{~min}$, the supernatant removed and dried under vacuum. The gel pieces were then extracted with $2.5 \%$ formic acid/50\% acetonitrile for 15 min before combining the supernatant with the original dried sample and drying once again under vacuum. Digests were reconstituted in $0.1 \mathrm{ml}$ of $1 \%$ formic acid in water and analysed by liquid chromatography followed by mass spectrometry (LC-MS) on an LC-Packings Ultimate HPLC system interfaced to an Applied Biosystems 4000 Q-TRAP system. Peptides were separated on a $150 \times 0.075 \mathrm{~mm}$ PepMapC18 column equilibrated in $0.1 \%$ formic acid in water at a flow rate of $350 \mathrm{nl} / \mathrm{min}$ and eluted with a discontinuous acetonitrile gradient at the same flow rate. The column eluate was mixed with a sheath liquid of $40 \%$ isopropanol/water at $300 \mathrm{nl} / \mathrm{min}$ using a capillary mixing Tee (Upchurch) and the combined flow plumbed into the microionspray head of the 4000 Q TRAP system mass spectrometer fitted with a New Objectives Picotip emitter (FS$3607515 \mathrm{~N}$ ). Electrospray mass spectrometry was performed in an automated precursor-of-79 duty cycle (6 sec total) in negative ion mode $(-2300 \mathrm{~V})$, with Q1 masses scanned between $500-2000 \mathrm{~m} / \mathrm{z}(3 \mathrm{sec})$, collided with a variable collision energy of -65 to $-110 \mathrm{~V}$ and a daughter ions detected in Q3 after trapping and expelling from the linear ion trap (50 ms fill time). 


\section{Results}

\section{DNA affinity chromatography to enrich DNA binding proteins}

Since ATM, ATR and DNA-PK bind to sites of DNA damage, where they become activated, we reasoned that important targets of these kinases might also be bound at these sites. With this in mind, we carried out affinity chromatography with a variety of synthetic DNA structures to enrich potential targets of these kinases. Linear double-stranded (ds) DNA, Holliday junction and "Y-fork" structures were made by annealing oligonucleotides. One oligonucleotide in each DNA structure had a 5'biotin group. In addition, all oligonucleotides were synthesised with phosphorothioate-substituted bases to prevent degradation by nucleases in cell extracts. Each structure, and single-stranded (ss) DNA, was immobilised on streptavidin-coated magnetic beads and incubated with whole extracts of HeLa cells, followed by western blotting with different antibodies.

We first tested the ability of the immobilised DNA structures to retain the known structure-specific DNA binding factors Mus81 [41] and hSlx1, the human orthologue of yeast Slx1 (unpublished) [38]. These are structure-dependent nucleases that cleave Holliday junctions and branched DNA structures, at least in vitro. As shown in Fig. 1A, endogenous Mus81 or transiently transfected FLAG-hS1x1 bound to the Y-fork and Holliday junction but not to dsDNA, ssDNA or empty beads. However, Ku70 which specifically bind DNA ends [42] also bound to the Y-fork and Holliday junction as well as to linear DNA, presumably due to the presence of free DNA ends. The large subunit of replication protein A that should bind only to ssDNA [43] was found to be associated not only with ssDNA but also with the Y-fork and Holliday junction. To reduce non-specific binding of factors like Ku to ends of the Holliday junction and Y-fork, and enrich structure-specific binding factors, competitor calf thymus dsDNA was included in the binding reaction. As shown in the last two panels of Fig. 1A, competitor dsDNA prevented binding of Ku70, but not hSlx1, to the Holliday junction and Y-fork. These conditions were used to enrich DNA binding factors that may be targets for the PIKKs.

\section{Identification as FUS as an in vitro substrate of PIKKs}

ATM, ATR and DNA-PK all phosphorylate target proteins on Ser/Thr residues that are followed by a Gln residue, referred to as S/T-Q motifs and all three kinases appear to have have identical specificity in vitro $[44,45]$. Since DNA-PK is an abundant protein that can be purified to homogeneity in active form, whereas ATM and ATR are present at low copy number in cells (data not shown), DNA-PK was used as a tool to identify DNA binding proteins that are phosphorylated by PIKKs.

DNA affinity chromatography of HeLa whole cell extracts was carried out using dsDNA and Holliday junctions as described above and beads were incubated with $\gamma$ ${ }^{32} \mathrm{P}$-labelled ATP- $\mathrm{Mg}^{2+}$ in the presence or absence of DNA-PK holoenzyme and dsDNA (that is necessary for DNA-PK to be active). Samples were then denatured and subjected to SDS/polyacrylamide gel electrophoresis, stained with colloidal coomassie stain followed by autoradiography (Fig. 1B). In the absence of DNA-PK, weak phosphorylation of a protein bound to both dsDNA- and Holliday junctioncoated beads, that migrated slightly more slowly than the 66kDa marker, was observed (Fig. 1B). This was probably due to one or more contaminating kinases that associate with these beads. However, when DNA-PK was added to the beads much stronger phosphorylation of a protein of approximately $66 \mathrm{kDa}$ was observed (Fig. 
1B). This radiolabelled species was excised from the gel, digested with trypsin and the resulting peptides were analysed on a 4000 Q-Trap mass spectrometer. This revealed the presence of two proteins: Ddx5, a member of the DEAD box family of RNA helicases, and FUS/TLS (data not shown). To determine which of these proteins is phosphorylated by DNA-PK, Ddx 5 and FUS were both immunoprecipitated from cell extracts and the precipitates were incubated with $\gamma-{ }^{32} \mathrm{P}-$ labelled ATP- $\mathrm{Mg}^{2+}$ in the presence or absence of DNA-PK holoenzyme and dsDNA. A band of approximately $66 \mathrm{kDa}$ in anti-FUS immunoprecipitates was strongly phosphorylated by DNA-PK, and this was inhibited by inclusion of the DNA-PK inhibitor NU7441 [36] but not the ATM inhibitor KU55933 [37] (Fig. 1C). This band was confirmed to be FUS by western blotting (Fig. 1C). It is unlikely that the band phosphorylated in the absence of DNA-PK is FUS since it had a slightly different molecular weight; the basal phosphorylation of this protein was not prevented by inclusion of NU7441 or KU55933 (Fig. 1C); this protein was not investigated further. DNA-PK did not catalyse detectable phosphorylation of any proteins in the anti-Ddx5 precipitates (data not shown).

To exclude the possibility that a protein co-immunoprecipitating with FUS, and not FUS itself, is phosphorylated by DNA-PK, FUS was expressed as a GST fusion protein in bacteria. GST-FUS, but not GST, was efficiently phosphorylated by DNAPK in a time-dependent manner with a stoichiometry of approximately fives moles of phosphate incorporated per mole of FUS (data not shown) indicating that FUS is phosphorylated efficiently by DNA-PK in vitro on at least five residues.

We next wished to identify the FUS residues phosphorylated by DNA-PK. Inspection of the amino acid sequence of FUS revealed twelve S/T-Q motifs, all located within the N-terminal 132 amino acids (Fig. 3C). FUS was phosphorylated to stoichiometry with DNA-PK in vitro and digested with chymotrypsin, since no cleavage site for trypsin was present in the N-terminal 132 amino acids of FUS. Chymotryptic peptides were separated by reversed-phase HPLC chromatography (Fig. 2A) and this revealed five radiolabelled peptides. The phosphorylated residue in each one was determined by solid-phase Edman sequencing (data not shown). This analysis identified the residues in FUS phosphorylated by DNA-PK as Ser26, Ser42, Ser61, Ser84 and Ser131 (Fig. 2B). All of these residues lie in S/T-Q motifs that conform to the consensus sequence for phosphorylation by the PIKKs, and are all found in the Ser/Thr-rich N-terminal region of FUS (Fig. 3C).

\section{Identification of FUS residues phosphorylated in vivo after DNA damage}

To determine if FUS becomes phosphorylated in vivo under conditions where PIKKs are activated, cells were exposed, or not, to IR (ionizing radiation) that causes doublestrand breaks. Cells were lysed, FUS was immunoprecipitated and precipitates were subjected to SDS/PAGE (Fig. 3A, upper panel). FUS was excised and digested with chymotrypsin, since there are no tryptic cleavage sites within the N-terminal Ser/Thrrich region of FUS that contains the S/T-Q motifs (Fig. 3C, lower panel).

Chymotryptic peptides were analysed on a 4000 Q-Trap mass spectrometer with precursor ion scanning to identify phosphopeptides. As shown in Fig. 3A (lower left panel), several phosphopeptides were detected in FUS isolated from untreated cells. However, several extra phosphopeptides were detected after exposure of cells to IR Fig. 3A (lower right panel). The sequences of these peptides is shown in Fig. 3B. It was not possible to use $\mathrm{ms} / \mathrm{ms}$ to pinpoint the exact residue(s) phosphorylated in these 
chymotryptic peptides; this is only possible with tryptic peptides since the positive charge of the Arg or Lys in tryptic peptides is required (N. Morrice, unpublished observations). However, all of the DNA damage-inducible FUS phosphopeptides mapped to the Ser/Thr-rich N-terminal region of FUS (Fig. 3C) that is also phosphorylated in vitro by DNA-PK (Fig. 2). In fact, all of the residues phosphorylated by DNA-PK, except Ser131, are located in the DNA damage-induced FUS phosphopeptides (Fig. 3C). This strongly suggests FUS is phosphorylated on one or more of these residues by PIKKs in vivo after exposure of cells to DNA damage.

\section{FUS is phosphorylated at Ser42 in vivo after exposure of cells to agents that cause double-strand breaks}

To confirm that DNA damage-induced phosphorylation of FUS occurred on one of the residues identified by mass spectrometry and in the in vitro analyses, phosphospecific antibodies were raised against Ser30 and Ser42 and affinity-purified using the phosphopeptide immunogen. Phosphopeptides corresponding to Ser30 failed to generate antibodies capable of recognising the phosphopeptide immunogen (data not shown). In contrast, dot blot analysis showed that affinity-purified phospho-specific antibodies raised against Ser42 recognised the correct phosphopeptide immunogen but not the corresponding non-phosphopeptide (Fig. 4A). These antibodies were then used to investigate FUS phosphorylation in vivo. HEK293 cells were exposed to IR, HU, MMS or ultraviolet (UV) light and allowed to recover for different times. Cell extracts were subjected to SDS-PAGE followed by western blotting. The antiphospho-Ser42 antibody recognised a single band in cell extracts, of exactly the same molecular weight as FUS, only after exposure of cells to DNA damage (Fig. 4B). Phosphorylation of Ser42 of FUS was apparent 15 min after exposure to IR and was still evident two hours post-irradiation (Fig. 4B). The kinetics of FUS phosphorylation were similar to those of IR-induced phosphorylation of SMC1, a known target of ATM, at Ser966 (Fig. 4B). In contrast exposure of cells to MMS (methylmethane sulphonate), a DNA alkylating agent, UV (ultraviolet) light or hydroxyurea (HU) that slows DNA replication, caused much weaker phosphorylation of FUS Ser42 even at the longest time points tested (Fig. 4B; data not shown). A number of proteomic studies were carried out by other groups to identify targets of PIKKs, and these involved immunoprecipitation of proteins from cell extracts using generic antiphospho S/T-Q antibodies [18] [19]. However, FUS was not identified in these screens.

Phosphorylation of SMC1 Ser966 was easily detectable in each case. To be certain that the antibodies we raised recognised phospho-Ser42 of FUS specifically, HEK293 cells were transiently transfected with HA (haemagluttinin)-tagged wild-type FUS or a mutant FUS in which Ser42 was mutated to alanine. Cell extracts were subjected to immunoprecipitation with anti-HA antibodies or with a non-specific (STAT3) antibody as control. As shown in Fig. 4C, wild-type FUS, but not the Ser42Ala mutant, was recognised by the anti-phospho-Ser42 antibody after immunoprecipitation with the anti-HA antibody but not with a non-specific antibody (anti-STAT3), after exposure of cells to IR. In contrast, the FUS Ser42Ala mutant is not recognised although present in similar amounts in anti-HA immunoprecipitates (Fig. 4C). These data indicate that FUS is phosphorylated at Ser42 in vivo primarily in response to IR that causes double-strand breaks. Since etoposide, an inhibitor of topopisomerase II that cause DSBs in cells also induced strong phosphorylation of FUS (Fig. 6B), it is likely that phosphorylation of FUS is primarily triggered by 
DSBs. It is worth noting that cell trasfection caused a basal phosphorylation of FUS to increase dramatically (data not shown), so western blots were exposed for short times, and therefore the band intensity in Fig. $4 \mathrm{C}$ is weaker than in Fig. 4B.

\section{Ser42 of FUS-CHOP is not phosphorylated after DNA damage}

The $\mathrm{t}(12 ; 16)(\mathrm{q} 13 ; \mathrm{p} 11)$ chromosomal translocation in human myxoid liposarcoma results in fusion of the N-terminal 266 amino acids of FUS to CHOP, a member of the C/EBP family of transcription (Fig. 5A) [22, 23]. In the FUS-CHOP fusion protein the RRM domain, and the zinc finger, of FUS is replaced by CHOP, but the Nterminal S/T-Q rich region of FUS that includes Ser42 is retained (Fig. 5A). To examine if Ser42 of FUS-CHOP is phosphorylated in response to DSBs, a HEK293 cell line stably expressing FLAG-tagged FUS-CHOP was generated. These cells were exposed to IR and allowed to recover for different times before lysis of cells and immunoprecipitation of with anti-FLAG antibodies. Although FLAG-FUS-CHOP was abundant in anti-FLAG immunoprecipiates, surprisingly no phosphorylation of Ser42 in the fusion protein was detected after exposure of cells to IR, even though endogenous FUS in the cell extracts was phosphorylated at Ser42 (Fig. 5B).

Since FUS-CHOP is not phosphorylated at Ser42 after IR, we reasoned that the Cterminal region of FUS missing from FUS-CHOP, that contains the RRM domain and zinc finger, may be required for phosphorylation by ATM. To test if the RRM domain or the zinc finger domain is required for FUS phosphorylation by ATM, Cys428, Cys427, Phe288, and Asp327 were all mutated to alanine and Phe305 to arginine. C428 and C427 are conserved in all C2-C2 zinc fingers while F288 is conserved in the RNP-2 submotif of RRM domains [46]. Mutation of the conserved Phe and Asp residues (F305 and D327 of FUS) which lie between the RNP-2 and RNP-1 regions in RRMs have been shown to abolish binding to RNAs [47]. HEK293 cells were transiently transfected with the resulting compound mutant, or wild-type FUS, fused to a HA epitope tag. The FUS Ser42Ala mutant was used as negative control. Both HA-FUS and the HA-FUS RRM/Zn mutant are phosphorylated at Ser42 after exposure to IR (Fig. 5C). Taken together, these data suggest that although the Cterminal region of FUS is required for phosphorylation of Ser42, the RRM and zinc finger are not involved.

\section{ATM, not DNA-PK, mediates IR-induced phosphorylation of FUS Ser42}

We next sought to determine the kinase(s) responsible for DSB-induced phosphorylation of FUS. Ser42 lies in a consensus sequence for ATM, ATR and DNA-PK; ATM and DNA-PK are activated in response to DSBs, but not UV or MMS, for example, which activate ATR. Since FUS is phosphorylated in response to DBSs, but only very weakly in response to MMS or UV, we reasoned that the most likely FUS kinases are ATM and DNA-PK. Pre-incubation of cells with NU7441, a specific inhibitor of DNA-PK [36] had no effect on phosphorylation of FUS induced by IR (Fig. 6A). In contrast the specific ATM inhibitor, KU55933 [48], severely reduced phosphorylation of FUS at Ser42 triggered by exposure of cells to IR or etoposide (Fig. 6B). These data indicate that DSB-induced phosphorylated of FUS is catalysed by ATM. 


\section{Discussion}

In this study we carried out DNA affinity chromatography to enrich potential targets of PIKKs. Using this approach we identified FUS, and found that it is phosphorylated efficiently by DNA-PK in vitro. The ability of FUS to bind to the different DNA species used in this study was not pursued, and it is not clear if FUS really binds DNA or if the binding we observed was a result of non-specific electrostatic interactions. It is not clear if FUS can really distinguish different DNA structures, for example, as suggested by Fig. 1B. PIKKs bind to sites of DNA damage in vivo [49]. Unlike many DNA damage-responsive proteins, FUS did not appear to form nuclear "foci" after DNA damage (data not shown) that are indicative of binding to sites of DNA damage. Nonetheless, the DNA affinity chromatography approach allowed us to discover that DNA-PK can phosphorylate FUS efficiently, revealing FUS as a potential in vivo target of PIKK family members.

Although FUS has a total of twelve S/T-Q motifs, all located in the in the N-terminal 132 amino acids of FUS, DNA-PK phosphorylated FUS in vitro with a stoichiometry of $5 \mathrm{~mol}$ phosphate per mol protein, suggesting phosphorylation of five residues. In vitro mapping revealed the five residues phosphorylated by DNA-PK - Ser26, Ser42, Ser61, Ser84 and Ser131 (Fig. 3C) - all of these residues lie in S/T-Q motifs. Q-Trap mass spectrometric analysis of FUS immunoprecipitated from cells after treatment with IR led to the identification of several chymotryptic phosphopeptides from the Nterminus of FUS that contained Ser26, Ser42, Ser61, Ser84. However, it was not possible to pinpoint precisely which residues in these peptides were phosphorylated because the positive charge that occurs in tryptic peptides (trypsin cleaves immediately after Lys/Arg residues), but not in chymotryptic peptides, is essential for phosphorylation site identification by $\mathrm{ms} / \mathrm{ms}$. Nonetheless, the good agreement between the FUS residues phosphorylated in vitro by DNA-PK and the serine residues in the chymotryptic phosphopeptides prompted further investigation. In this light, an affinity-purified antibody raised against phospho-Ser42 demonstrated clearly that FUS is phosphorylated at this residue primarily in response to IR or etoposide, agents that cause DSBs. In contrast, FUS was only weakly phosphorylated in response to MMS, UV or HU (Fig. 4B), The spectrum of agents that induced FUS phosphorylation indicated that ATM or DNA-PK were the most likely FUS kinases. Although DNA-PK phosphorylates FUS efficiently in vitro, NU7441 a specific inhibitor of DNA-PK has no effect on FUS Ser42 phosphorylation in vivo. In contrast, IR- or etoposide-induced FUS phosphorylation was prevented by pre-incubation of cells with KU55933, a specific inhibitor of ATM. Therefore ATM phosphorylates FUS at Ser42 in vivo. While the present study was underway, a number of proteomic studies were carried out by other groups to identify targets of PIKKs, and these involved immunoprecipitation of proteins from cell extracts using generic antiphospho S/T-Q antibodies [18] [19]. However, FUS was not identified in these studies. In one of these studies, trypsin was used to cleave proteins in extracts before immunoprecipition by the anti-phospho S/T-Q antibody. The region of FUS phosphorylated by ATM is not cleaved by trypsin and therefore would have been too large for mass spectrometric analysis and consequent identification as a PIKK target.

Ser42 of FUS lies in the region of FUS that becomes fused to transcription factors in sarcomas and leukaemias (Fig. 5A) [22, 23]. We tested the FUS-CHOP fusion protein, stably expressed in HEK293 cells, for phosphorylation after IR. Intriguingly, although wild-type FUS was phosphorylated in response to IR, no phosphorylation of 
FUS-CHOP was detected (Fig. 5B). The basis for this observation is not yet clear but we reasoned that the C-terminal portion of FUS that is missing from oncogenic FUS fusion proteins could be required for $\mathrm{N}$-terminal phosphorylation. The $\mathrm{C}$-terminus of FUS contains two conserved domains, a zinc finger domain and an RRM domain (Fig. 5A). However, these domains do not appear to be required for phosphorylation of FUS as mutation of conserved residues in these domains does not affect phosphorylation on Ser42 after exposure to IR (Fig. 5C). The most likely explanation for these data is the C-terminal region of FUS missing from FUS-CHOP, contains a docking site for ATM and this will be interesting to investigate. It is also possible that the C-terminus of FUS missing from FUS-CHOP is required to co-localise FUS with ATM at double-strand breaks. However, we could not detect nuclear "foci" typical of proteins that are stably retained at sites of DNA damage (data not shown).

Like mice lacking ATM, mice lacking FUS are hypersensitive to IR and show defects in spermatogenesis resulting from perturbations in meiotic synapses [20] and loss of FUS or ATM causes high levels of chromosomal instability [33]. The defects in meiosis are consistent with the interruption of an early step in homologous recombination. In our hands, however, the efficiency of double-strand break repair in cells from FUS $-/-$ mice is indistinguishable from FUS $-/+$ mice.

We would very much like to test the impact of ATM-catalysed phosphorylation on FUS function. However, the role of FUS in the cellular response to DNA damage is not yet clear but is under investigation in this laboratory. The IR sensitivity of embryonic fibroblasts isolated from FUS $-/$ - mice is slight compared with cells from mice defective in other DNA damage-responsive proteins [20] (data not shown), and the severe sensitivity of the FUS - - - whole mice to killing by IR may be due to effects on specific cells types. Given that FUS has been shown to bind RNA, and has RNA binding motifs, it is possible that FUS regulates DNA damage-induced transcription or splicing or other aspects of RNA metabolism linked with DNA damage responses. This is currently under investigation in this laboratory.

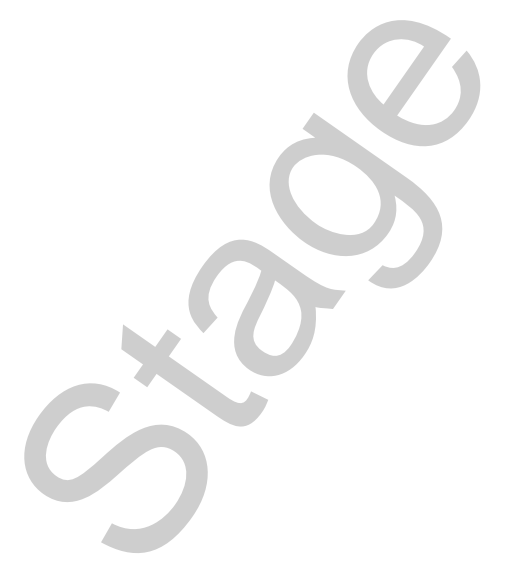




\section{Acknowledgements}

We are grateful to Drs. Maria Jasin, Terence Rabbitts, David Ron and Graeme Smith for useful reagents. This work was funded by the Medical Research Council (MRC) of the United Kingdom. 


\section{Figure legends}

\section{Fig. 1. Identification of potential substrates of PIKKs using DNA affinity chromatography}

(A) Equimolar amounts of the relevant DNA structures, in which one oligonucleotide had a 5' biotin moiety, were immobilised on streptavidin-coated magnetic beads and incubated with whole extracts of HEK293 cells. After extensive washing, proteins bound to the beads were eluted and subjected to SDS-PAGE followed by western blot analysis with the antibodies indicated. In the lowest two panels, an excess of competitor calf thymus DNA $(25 \mu \mathrm{g} / \mathrm{ml})$ was added to the extracts during the binding reactions. (B) The relevant DNA structures bound to magnetic beads were incubated with extracts of HEK293 cells in the presence of calf thymus competitor DNA, as in A. Beads were washed and incubated with $\gamma-{ }^{32} \mathrm{P}$-ATP in kinase buffer, in the presence or absence of DNA-PK as described in Materials and Methods. Proteins bound to beads were subjected to autoradiography. Recombinant p53 was used as a positive control in the kinase assay. (C) Extracts of HeLa cells were subjected to immunoprecipitation with anti-FUS antibodies or non-specific (anti-HA) antibodies. Precipitates were incubated with $\gamma-{ }^{32} \mathrm{P}$-ATP in kinase buffer, in the presence or absence of DNA-PK as described in Materials and Methods. Where indicated, the DNA-PK inhibitor NU7441 or the ATM inhibitor KU55933 were included in phosphorylation reaction. Immunoprecipitates were subjected to SDS-PAGE followed by western blotting, staining with Coomassie or autoradiography. Recombinant PHAS-1 was used as a positive control for DNA-PK activity.

\section{Fig. 2. Identification of residues in FUS phosphorylated by DNA-PK in vitro}

(A) FUS was phosphorylated to stoichiometry with DNA-PK in the presence of $\gamma^{-32} \mathrm{P}$ ATP, subjected to SDS-PAGE and the FUS band was excised and digested with chymotrypsin. The resulting peptides were subjected to reversed-phase HPLC. ${ }^{32} \mathrm{P}$ radioactivity was detected by on-line Cerenkov counting. (B) Amino acid sequence and phosphorylated residues of the chymotryptic peptides from peaks shown in A.

\section{Fig. 3. Identification of residues in FUS phosphorylated after DNA damage in} vivo

(A) HEK293 cells were treated with ionizing radiation (10 Gy; right panel), or not (left panel) and after cell lysis, FUS was immunoprecipitated and subjected to SDSPAGE (upper panel). FUS was excised, digested with chymotrypsin and the resulting peptides were analysed by LC-MS with precursor ion scanning on a 4000 Q Trap system (lower panels). Each peak corresponds to a phosphopeptide, and those phosphopeptides that increase in abundance after exposure of cells to damaging agents are labelled 1-6 (lower right panel). (B) Sequences of the chymotrypic phosphopeptides from A. (C) Schematic diagram of domain architecture FUS and primary amino acid sequence. Upper panel: the N-terminal S/T-Q-rich region, the RRM (RNA recognition motif) domain, the RGG repeat regions and the zinc-finger are indicated. Lower panel: The amino acid sequence of FUS. The region corresponding to the overlapping chymotryptic phosphopeptides is underlined, and the residues phosphorylated by DNA-PK in vitro are highlighted in grey.

\section{Fig. 4. FUS is phosphorylated at Ser42 in vivo primarily in response to agents} that cause double-strand breaks

(A) The indicated amounts of the relevant phosphopeptides and non-phosphopeptides were diluted in water, spotted onto nitrocellulose and allowed to dry. The membrane 
was then subjected to western blot analysis with an FUS anti-phospho-Ser42 antibody. (B) HEK293 cells were left untreated or exposed to ionizing radiation (IR; $10 \mathrm{~Gy})$ or UV light $\left(30 \mathrm{Jm}^{-2}\right)$ and allowed to recover for the times indicated. Alternatively cells were treated with methyl methane sulphonate (MMS; $0.01 \%$ ) or hydroxyurea $(\mathrm{HU} ; 10 \mathrm{mM})$ for the times indicated. After cell lysis, extracts were subjected to SDS-PAGE followed by western blot analysis with the indicated antibody. (C) HEK293 cells were transiently transfected with wild-type HA-FUS (WT), or HA-FUS in which Ser42 was mutated to alanine (S42A), and exposed, or not, to IR (10 Gy). Cell extracts were subjected to immunoprecipitation with anti-HA antibodies or with non-specific antibodies (anti-STAT3) as control.

Immunoprecipitates were subjected to SDS-PAGE followed by western blot analysis with the indicated antibody (upper panel). The lower panel shows western blot analysis of the cell extracts.

Fig. 5. Ser42 of FUS-CHOP fusion is not phosphorylated exposure of cells to IR (A) Schematic representation of the oncogenic FUS-CHOP fusion protein that arises as a result of a $\mathrm{t}(12 ; 16)(\mathrm{q} 13 ; \mathrm{p} 11)$ chromosomal translocation. The FUS portion is shaded in pink and the CHOP portion is shaded in purple. A part of the 5' untranslated region of CHOP region that is translated in FUS-CHOP is shown in black. (B) FLAG-FUS-CHOP was immunoprecipitated from extract of HEK293 cells stably expressing this protein before or after exposure of cells to IR. Cell lysates (lefthand panels) and anti-FLAG immunoprecipitates (right-hand panels) were subjected to SDS-PAGE followed by western blot analysis with the anti-phospho-Ser42 antibody. Membranes were stripped and reprobed with the indicated antibody to check protein loading. (C) Wild-type HA-FUS or HA-FUS with mutations in both the RRM domain and the zinc-finger domain (Cys428, Cys427, Phe288, Phe305 and Asp327), or HA-FUS Ser42Ala were immunoprecipitated from HEK293 cells before or after exposure of cells to IR. Immunoprecipitates were subjected to SDS-PAGE followed by western blot analysis with the anti-phospho-Ser42 antibody. Membranes were stripped and reprobed with anti-HA antibody to check protein loading.

Fig. 6. DSB-induced phosphorylation of FUS requires ATM and not DNA-PK (A) HEK293 cells were pre-incubated with DMSO vehicle or with NU7441 (10 $\mu \mathrm{M})$ for $1 \mathrm{hr}$ before exposure to IR (10 Gy). Cell extracts were subjected to SDS-PAGE followed by western blot analysis with the indicated antibody. (B) Same as (A), except that cells were pre-incubated with DMSO vehicle or with KU55933 $(10 \mu \mathrm{M})$ for $1 \mathrm{hr}$ before exposure to IR (10 Gy) or treatment with etoposide $(30 \mu \mathrm{M})$ for the times indicated. 


\section{References}

1 Shiloh, Y. (2003) ATM and related protein kinases: safeguarding genome integrity. Nat. Rev. Cancer 3, 155-168

2 Abraham, R. T. (2004) PI 3-kinase related kinases: 'big' players in stressinduced signaling pathways. DNA Repair (Amst.) 3, 883-887

3 Helt, C. E., Cliby, W. A., Keng, P. C., Bambara, R. A. and O'Reilly, M. A. (2005) Ataxia telangiectasia mutated (ATM) and ATM and Rad3-related protein exhibit selective target specificities in response to different forms of DNA damage. J. Biol. Chem. 280, 1186-1192

4 Falck, J., Coates, J. and Jackson, S. P. (2005) Conserved modes of recruitment of ATM, ATR and DNA-PKcs to sites of DNA damage. Nature 434, 605-611

5 Durocher, D. and Jackson, S. P. (2001) DNA-PK, ATM and ATR as sensors of DNA damage: variations on a theme? Curr. Opin. Cell Biol. 13, 225-231

6 Traven, A. and Heierhorst, J. (2005) SQ/TQ cluster domains: concentrated ATM/ATR kinase phosphorylation site regions in DNA-damage-response proteins. Bioessays 27, 397-407

7 Ward, J. F. (1985) Biochemistry of DNA lesions. Radiat. Res. Suppl. 8, S103111

8 Saleh-Gohari, N., Bryant, H. E., Schultz, N., Parker, K. M., Cassel, T. N. and Helleday, T. (2005) Spontaneous homologous recombination is induced by collapsed replication forks that are caused by endogenous DNA single-strand breaks. Mol. Cell. Biol. 25, 7158-7169

9 Bassing, C. H. and Alt, F. W. (2004) The cellular response to general and programmed DNA double strand breaks. DNA Repair (Amst.) 3, 781-796

10 Lieber, M. R., Ma, Y., Pannicke, U. and Schwarz, K. (2004) The mechanism of vertebrate nonhomologous DNA end joining and its role in $\mathrm{V}(\mathrm{D}) \mathrm{J}$ recombination. DNA Repair (Amst.) 3, 817-826

11 Wyman, C., Ristic, D. and Kanaar, R. (2004) Homologous recombinationmediated double-strand break repair. DNA Repair (Amst.) 3, 827-833

12 Sung, P. (1994) Catalysis of ATP-dependent homologous DNA pairing and strand exchange by yeast RAD51 protein. Science 265, 1241-1243

13 Wu, L. and Hickson, I. D. (2003) The Bloom's syndrome helicase suppresses crossing over during homologous recombination. Nature 426, 870-874

14 Smith, G. C. and Jackson, S. P. (1999) The DNA-dependent protein kinase. Genes Dev. 13, 916-934

15 Riballo, E., Critchlow, S. E., Teo, S. H., Doherty, A. J., Priestley, A., Broughton, B., Kysela, B., Beamish, H., Plowman, N., Arlett, C. F., Lehmann, A. R., Jackson, S. P. and Jeggo, P. A. (1999) Identification of a defect in DNA ligase IV in a radiosensitive leukaemia patient. Curr. Biol. 9, 699-702

16 Jeggo, P. A., Carr, A. M. and Lehmann, A. R. (1998) Splitting the ATM: distinct repair and checkpoint defects in ataxia-telangiectasia. Trends Genet. 14, 312-316

17 Morrison, C., Sonoda, E., Takao, N., Shinohara, A., Yamamoto, K. and Takeda, S. (2000) The controlling role of ATM in homologous recombinational repair of DNA damage. EMBO J. 19, 463-471

18 Matsuoka, S., Ballif, B. A., Smogorzewska, A., McDonald, E. R., 3rd, Hurov, K. E., Luo, J., Bakalarski, C. E., Zhao, Z., Solimini, N., Lerenthal, Y., Shiloh, Y., Gygi, S. P. and Elledge, S. J. (2007) ATM and ATR substrate analysis reveals extensive protein networks responsive to DNA damage. Science 316, $1160-1166$ 
19 Mu, J. J., Wang, Y., Luo, H., Leng, M., Zhang, J., Yang, T., Besusso, D., Jung, S. Y. and Qin, J. (2007) A proteomic analysis of ataxia telangiectasiamutated (ATM)/ATM-Rad3-related (ATR) substrates identifies the ubiquitinproteasome system as a regulator for DNA damage checkpoints. J. Biol. Chem. 282, 17330-17334

20 Kuroda, M., Sok, J., Webb, L., Baechtold, H., Urano, F., Yin, Y., Chung, P., de Rooij, D. G., Akhmedov, A., Ashley, T. and Ron, D. (2000) Male sterility and enhanced radiation sensitivity in TLS(-/-) mice. EMBO J. 19, 453-462

21 Chun, H. H. and Gatti, R. A. (2004) Ataxia-telangiectasia, an evolving phenotype. DNA Repair (Amst.) 3, 1187-1196

22 Crozat, A., Aman, P., Mandahl, N. and Ron, D. (1993) Fusion of CHOP to a novel RNA-binding protein in human myxoid liposarcoma. Nature 363, 640644

23 Rabbitts, T. H., Forster, A., Larson, R. and Nathan, P. (1993) Fusion of the dominant negative transcription regulator CHOP with a novel gene FUS by translocation $\mathrm{t}(12 ; 16)$ in malignant liposarcoma. Nat. Genet. 4, 175-180

24 May, W. A., Lessnick, S. L., Braun, B. S., Klemsz, M., Lewis, B. C., Lunsford, L. B., Hromas, R. and Denny, C. T. (1993) The Ewing's sarcoma EWS/FLI-1 fusion gene encodes a more potent transcriptional activator and is a more powerful transforming gene than FLI-1. Mol. Cell. Biol. 13, 73937398

25 Zinszner, H., Albalat, R. and Ron, D. (1994) A novel effector domain from the RNA-binding protein TLS or EWS is required for oncogenic transformation by CHOP. Genes Dev. 8, 2513-2526

26 Arvand, A. and Denny, C. T. (2001) Biology of EWS/ETS fusions in Ewing's family tumors. Oncogene 20, 5747-5754

27 Iko, Y., Kodama, T. S., Kasai, N., Oyama, T., Morita, E. H., Muto, T., Okumura, M., Fujii, R., Takumi, T., Tate, S. and Morikawa, K. (2004) Domain architectures and characterization of an RNA-binding protein, TLS. J. Biol. Chem. 279, 44834-44840

28 Morohoshi, F., Ootsuka, Y., Arai, K., Ichikawa, H., Mitani, S., Munakata, N. and Ohki, M. (1998) Genomic structure of the human RBP56/hTAFII68 and FUS/TLS genes. Gene 221, 191-198

29 Zinszner, H., Sok, J., Immanuel, D., Yin, Y. and Ron, D. (1997) TLS (FUS) binds RNA in vivo and engages in nucleo-cytoplasmic shuttling. J. Cell Sci. $110,1741-1750$

30 Prasad, D. D., Ouchida, M., Lee, L., Rao, V. N. and Reddy, E. S. (1994) TLS/FUS fusion domain of TLS/FUS-erg chimeric protein resulting from the $\mathrm{t}(16 ; 21)$ chromosomal translocation in human myeloid leukemia functions as a transcriptional activation domain. Oncogene 9, 3717-3729

31 Calvio, C., Neubauer, G., Mann, M. and Lamond, A. I. (1995) Identification of hnRNP P2 as TLS/FUS using electrospray mass spectrometry. RNA 1, 724733

32 Meissner, M., Lopato, S., Gotzmann, J., Sauermann, G. and Barta, A. (2003) Proto-oncoprotein TLS/FUS is associated to the nuclear matrix and complexed with splicing factors PTB, SRm160, and SR proteins. Exp. Cell Res. 283, 184195

33 Hicks, G. G., Singh, N., Nashabi, A., Mai, S., Bozek, G., Klewes, L., Arapovic, D., White, E. K., Koury, M. J., Oltz, E. M., Van Kaer, L. and Ruley, H. E. (2000) Fus deficiency in mice results in defective B-lymphocyte 
development and activation, high levels of chromosomal instability and perinatal death. Nat. Genet. 24, 175-179

34 Bertrand, P., Akhmedov, A. T., Delacote, F., Durrbach, A. and Lopez, B. S. (1999) Human POMp75 is identified as the pro-oncoprotein TLS/FUS: both POMp75 and POMp100 DNA homologous pairing activities are associated to cell proliferation. Oncogene 18, 4515-4521

35 Riggi, N. and Stamenkovic, I. (2007) The Biology of Ewing sarcoma. Cancer Lett. 254, 1-10

36 Hardcastle, I. R., Cockcroft, X., Curtin, N. J., El-Murr, M. D., Leahy, J. J., Stockley, M., Golding, B. T., Rigoreau, L., Richardson, C., Smith, G. C. and Griffin, R. J. (2005) Discovery of potent chromen-4-one inhibitors of the DNA-dependent protein kinase (DNA-PK) using a small-molecule library approach. J. Med. Chem. 48, 7829-7846

37 Hickson, I., Zhao, Y., Richardson, C. J., Green, S. J., Martin, N. M., Orr, A. I., Reaper, P. M., Jackson, S. P., Curtin, N. J. and Smith, G. C. (2004) Identification and characterization of a novel and specific inhibitor of the ataxia-telangiectasia mutated kinase ATM. Cancer Res. 64, 9152-9159

38 Fricke, W. M. and Brill, S. J. (2003) Slx1-Slx4 is a second structure-specific endonuclease functionally redundant with Sgs1-Top3. Genes Dev. 17, 17681778

39 Kingston, R. E., Chen, C. A. and Okayama, H. (2003) Calcium phosphate transfection. Curr. Protoc. Cell Biol. Chapter 20, Unit 2023

40 Campbell, D. G. a. M., N. (2002) Identification of protein phosphorylation sites by a combination of mass spectrometry and solid phase Edman sequencing. J. Biomol. Tech. 13, 119-130

41 Ciccia, A., Constantinou, A. and West, S. C. (2003) Identification and characterization of the human mus81-eme1 endonuclease. J. Biol. Chem. 278, 25172-25178

42 Featherstone, C. and Jackson, S. P. (1999) Ku, a DNA repair protein with multiple cellular functions? Mutat. Res. 434, 3-15

43 Sancar, A. (1996) DNA excision repair. Annu Rev Biochem 65, 43-81

44 Kim, S. T., Lim, D. S., Canman, C. E. and Kastan, M. B. (1999) Substrate specificities and identification of putative substrates of ATM kinase family members. J. Biol. Chem. 274, 37538-37543

45 O'Neill, T., Dwyer, A. J., Ziv, Y., Chan, D. W., Lees-Miller, S. P., Abraham, R. H., Lai, J. H., Hill, D., Shiloh, Y., Cantley, L. C. and Rathbun, G. A. (2000) Utilization of oriented peptide libraries to identify substrate motifs selected by ATM. J. Biol. Chem. 275, 22719-22727

46 Maris, C., Dominguez, C. and Allain, F. H. (2005) The RNA recognition motif, a plastic RNA-binding platform to regulate post-transcriptional gene expression. FEBS J. 272, 2118-2131

47 Sakai, K., Kitagawa, Y. and Hirose, G. (1999) Analysis of the RNA recognition motifs of human neuronal ELAV-like proteins in binding to a cytokine mRNA. Biochem. Biophys. Res. Commun. 256, 263-268

48 Hickson, I., Zhao, Y., Richardson, C. J., Green, S. J., Martin, N. M., Orr, A. I., Reaper, P. M., Jackson, S. P., Curtin, N. J. and Smith, G. C. (2004) Identification and characterization of a novel and specific inhibitor of the ataxia-telangiectasia mutated kinase ATM. Cancer Res. 64, 9152-9159. Shiloh, Y. (2001) ATM and ATR: networking cellular responses to DNA damage. Curr. Opin. Genet. Dev. 11, 71-77. 
Biochemical Journal Immediate Publication. Published on 11 Jul 2008 as manuscript BJ20081135

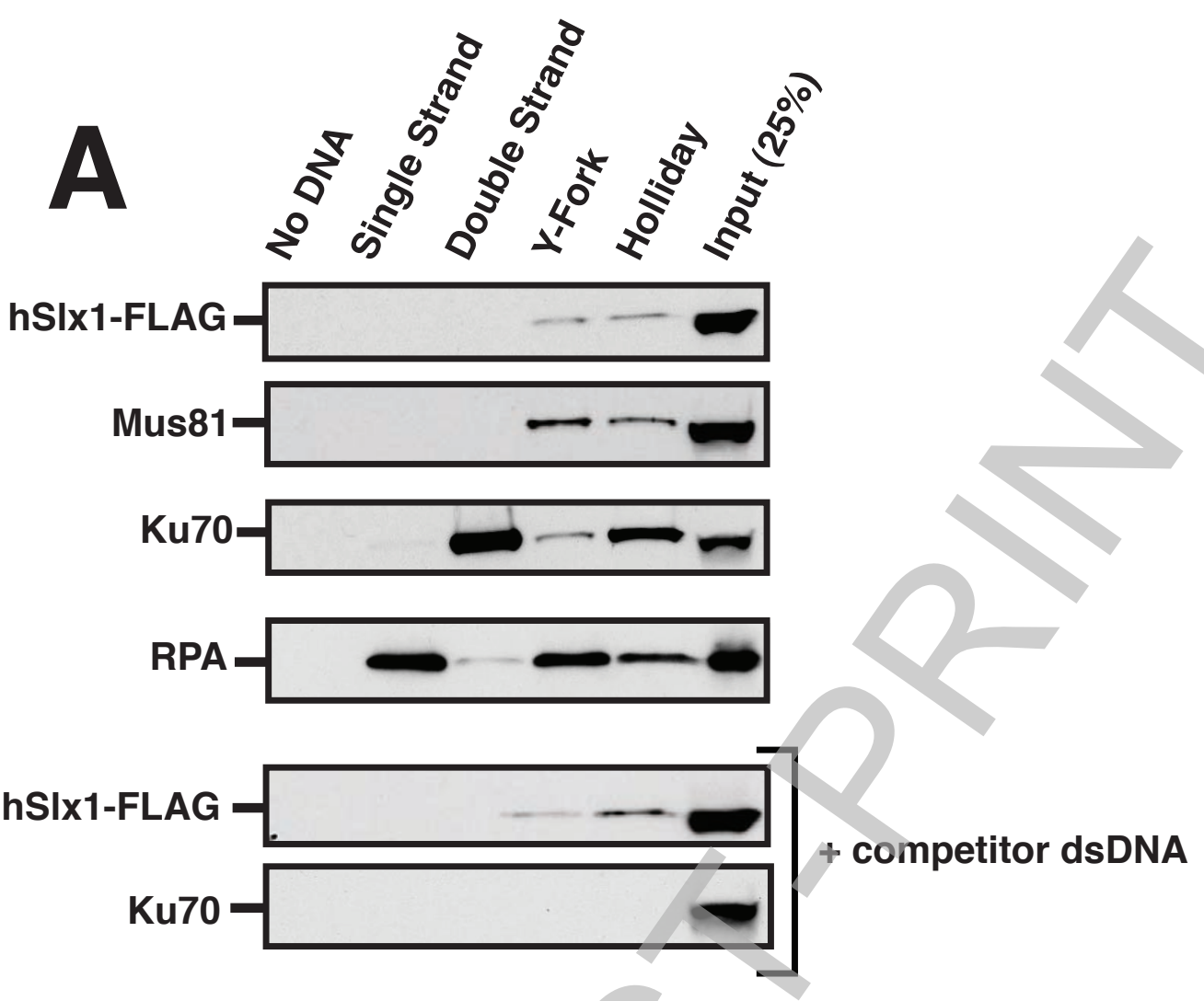

B

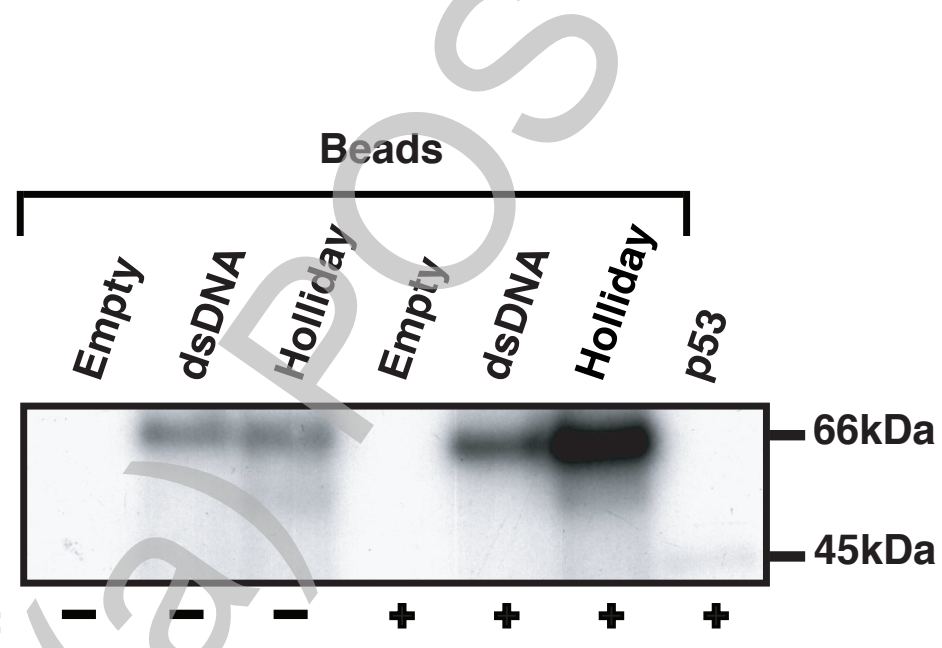

DNA-PK:

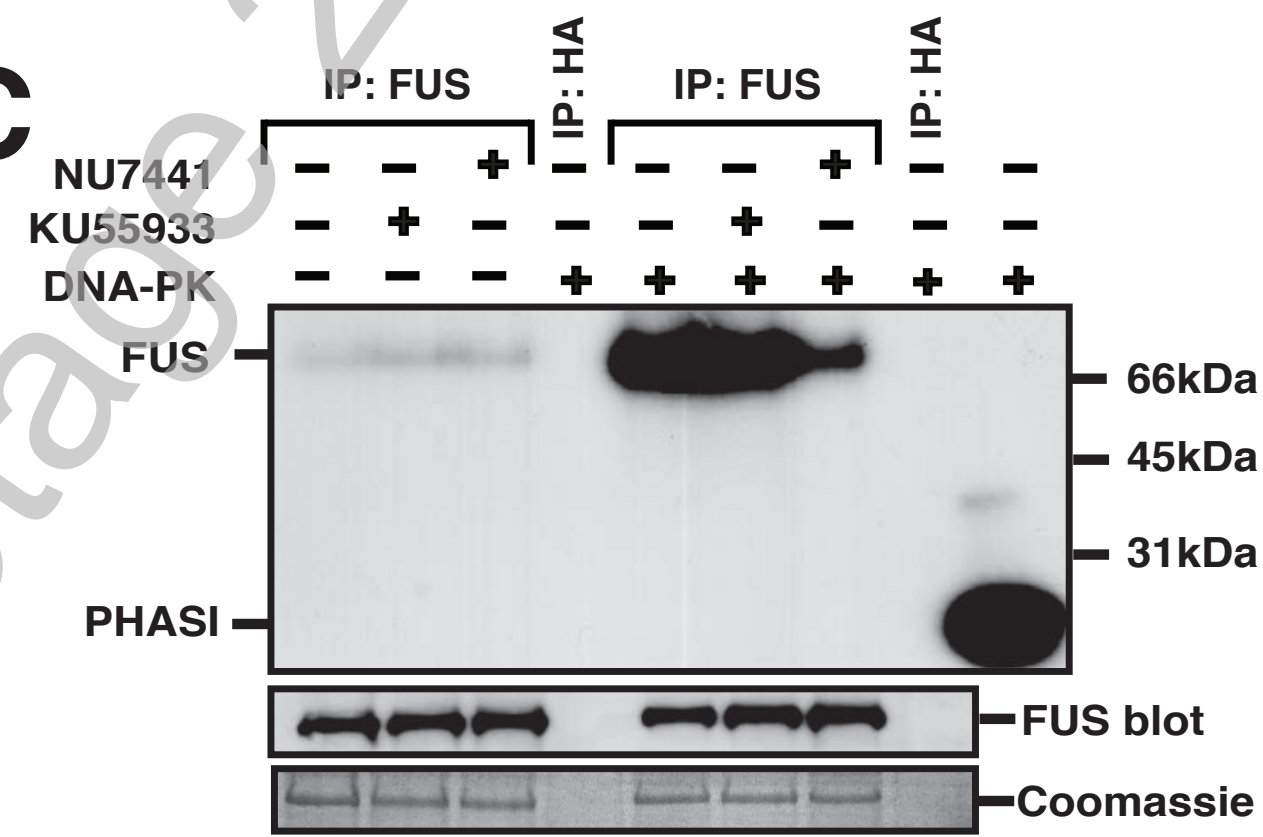

Licenced copy. Copying is not permitted, except with prior permission and as allowed by law.

(c) 2008 The Authors Journal compilation (c) 2008 Biochemical Society 


\section{A.}

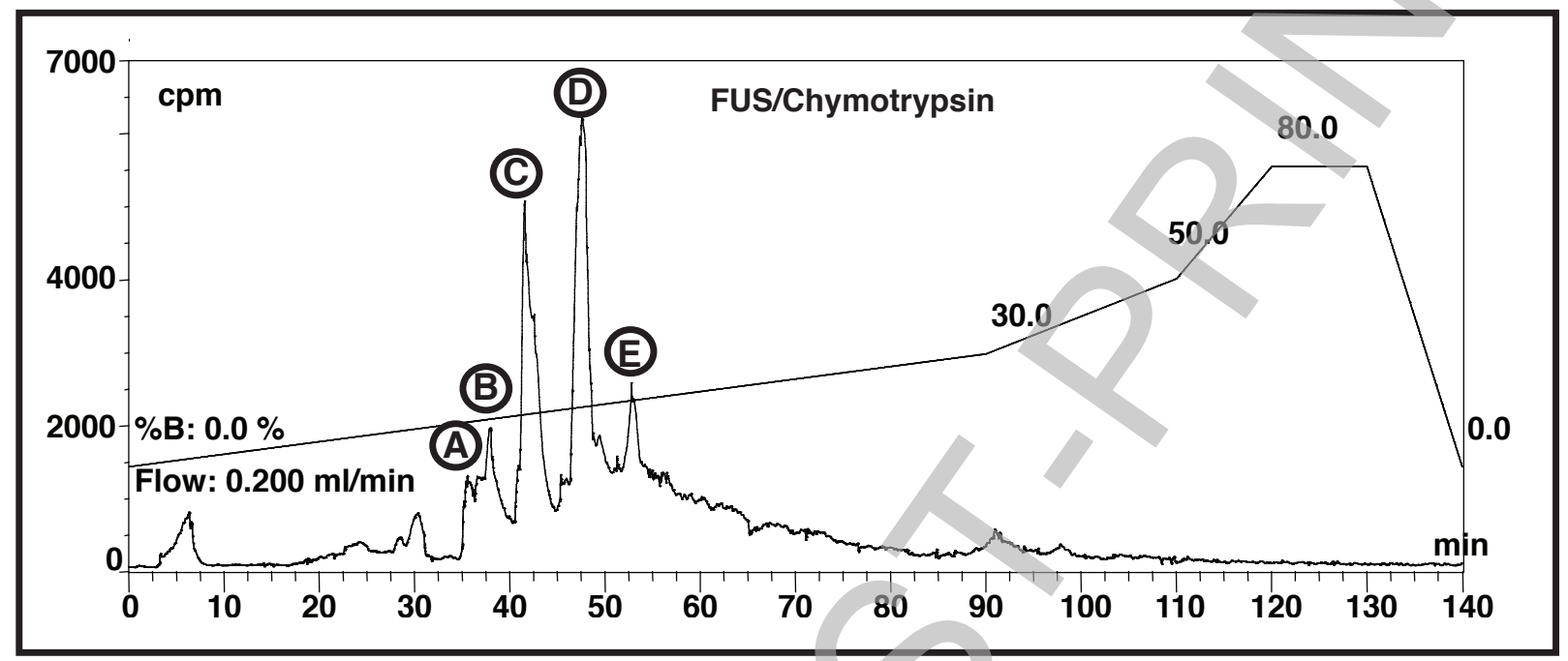

B.

\begin{tabular}{|c|c|c|}
\hline HPLC peak & Residue phosphorylated & Peptide sequence \\
\hline A & Serine 61 & YGQSQNTGYGTQSTPQGYGS \\
\hline B & Serine 84 & GSTGGYGSSQSSQSSYPGYG \\
\hline C & Serine 42 & SGYSQSTDTSSGYGQSSYSS \\
\hline D & Serine 131 & GQPQSGSYSQQPSYGGQQQS \\
\hline E & Serine 26 & GAYPTQPGQGYSQQSSQPYG \\
\hline
\end{tabular}



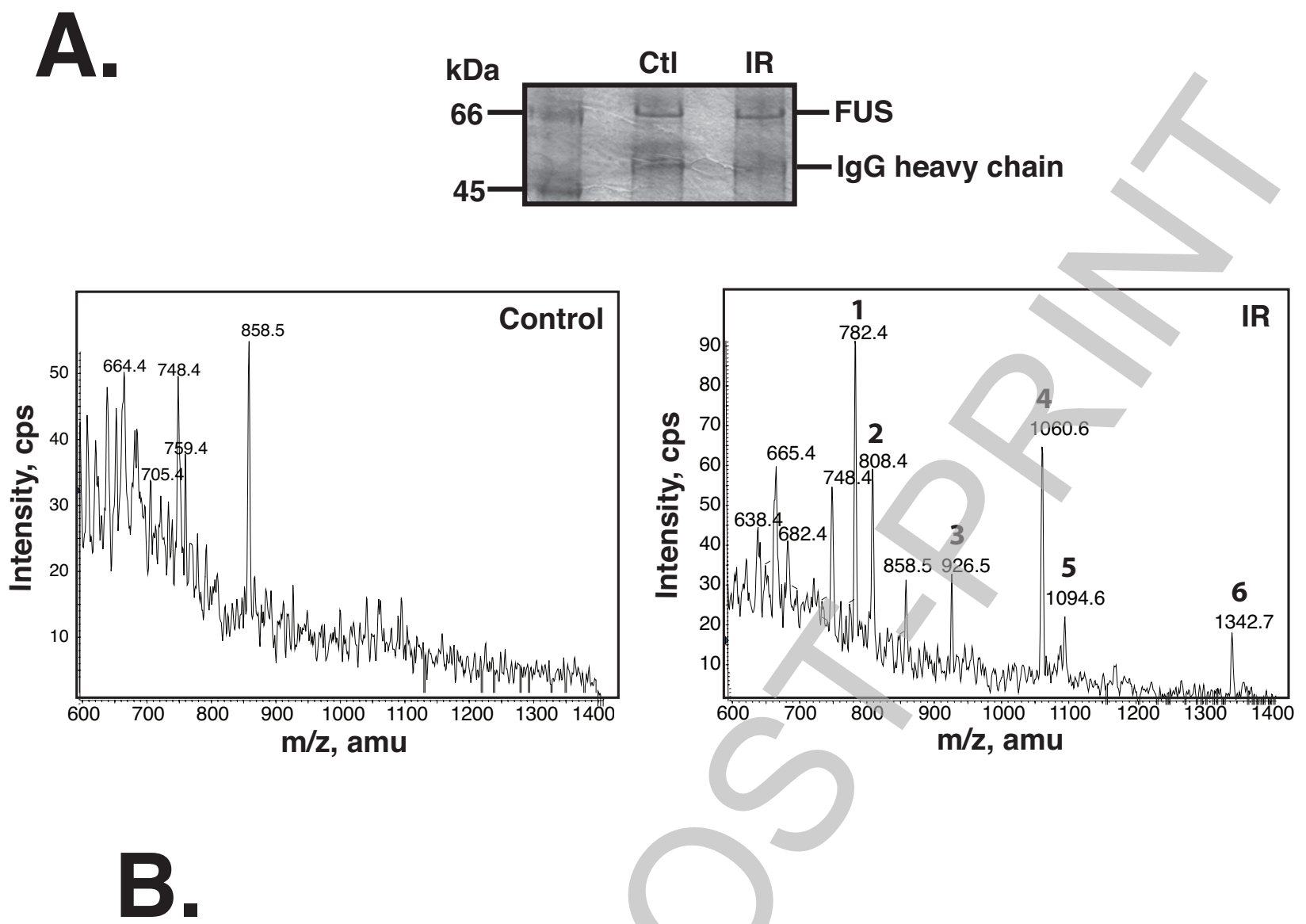

\begin{tabular}{|c|c|l|}
\hline Peptide & Residues & Sequence \\
\hline 1 & $26-38$ & SQQSSQPYGQQSY \\
\hline 2 & $76-91$ & GSTGGYGSSQSSQSSY \\
\hline 3 & $39-55$ & SGYSQSTDTSGYGQSSY \\
\hline 4 & $15-33$ & GAYPTQPGQGYSQQSSQPY \\
\hline 5 & $56-75$ & SSYGQSQNTGYGTQSTPQGY \\
\hline 6 & $15-38$ & GAYPTQPGQGYSQQSSQPYGQQSY \\
\hline
\end{tabular}
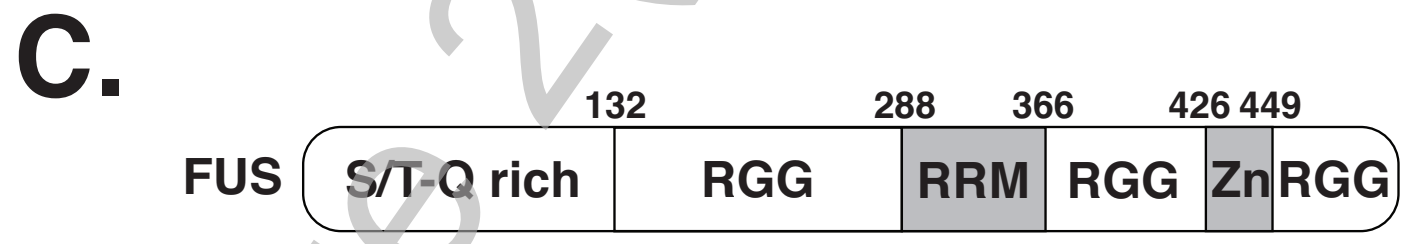

MASNDYTQQA TQSYGAYPTQ PGQGYSQQSS QPYGQQSYSG YSQSTDTSGY GQSSYSSYGQ SQNTGYGTQS TPQGYGSTGG YGSSQSSQSS YGQQSSYPGY GQQPAPSSTS GSYGSSSQSS SYGQPQSGSY SQQPSYGGQQ QSYGQQQSYN PPQGYGQQNQ YNSSSGGGGG GGGGGNYGQD QSSMSSGGGS GGGYGNQDQS GGGGSGGYGQ QDRGGRGRGG SGGGGGGGGG GYNRSSGGYE PRGRGGGRGG RGGMGGSDRG GFNKFGGPRD QGSRHDSEQD NSDNNTIFVQ GLGENVTIES VADYFKQIGI IKTNKKTGQP MINLYTDRET GKLKGEATVS FDDPPSAKAA IDWFDGKEFS GNPIKVSFAT RRADFNRGGG NGRGGRGRGG PMGRGGYGGG GSGGGGRGGF PSGGGGGGGQ QRAGDWKCPN PTCENMNFSW RNECNQCKAP KPDGPGGGPG GSHMGGNYGD DRRGGRGGYD RGGYRGRGGD RGGFRGGRGG GDRGGFGPGK MDSRGEHRQD RRERPY 
Biochemical Journal Immediate Publication. Published on 11 Jul 2008 as manuscript BJ20081135

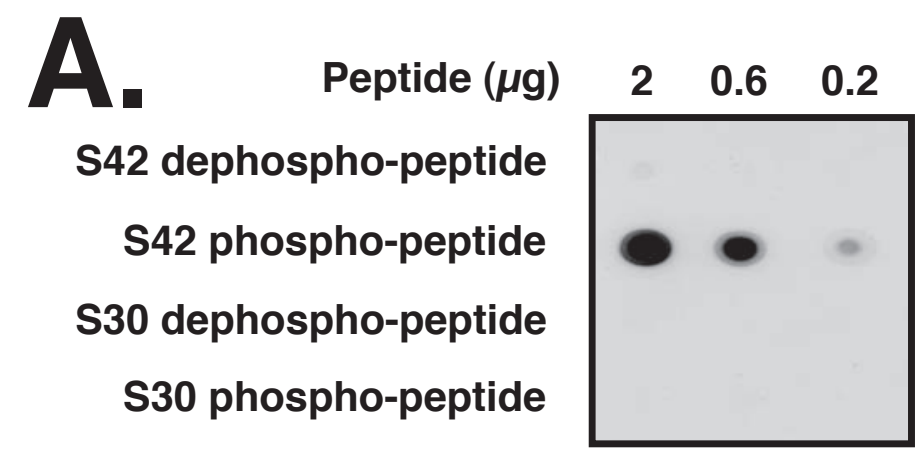

B.

IR

UV
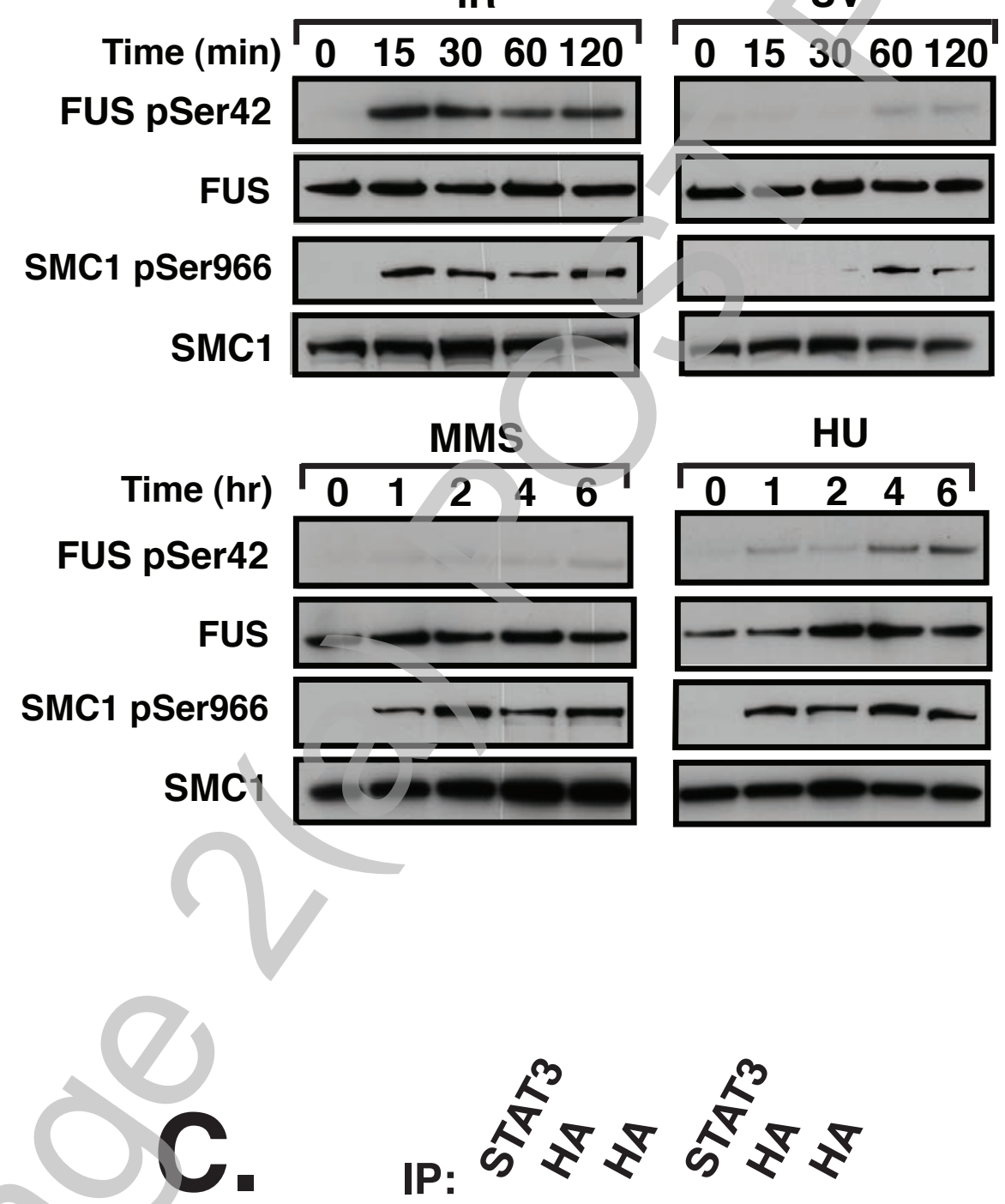

IP:

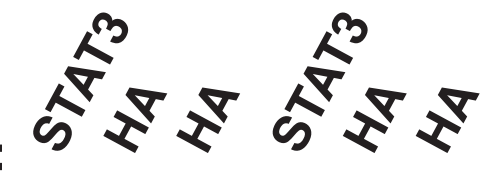

IR:

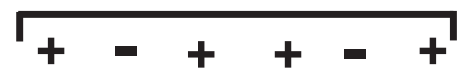

FUS pSer42

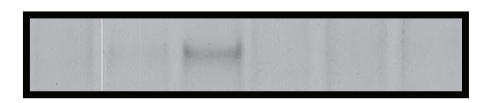

anti-HA

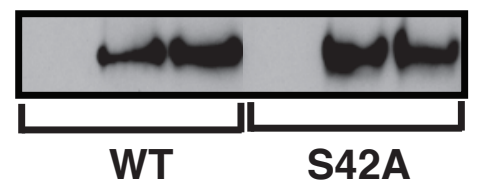



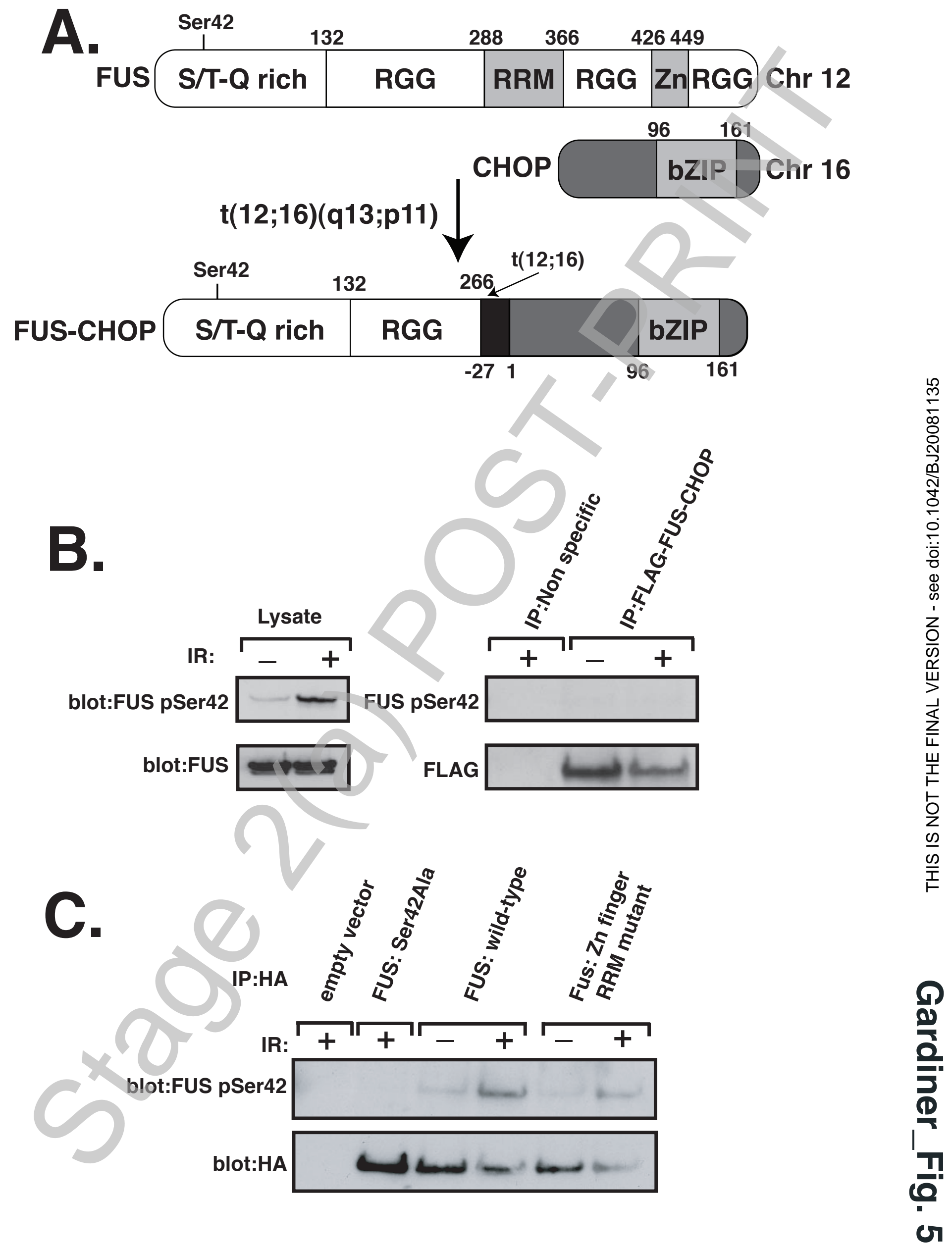

Licenced copy. Copying is not permitted, except with prior permission and as allowed by law. (C) 2008 The Authors Journal compilation (C) 2008 Biochemical Society 

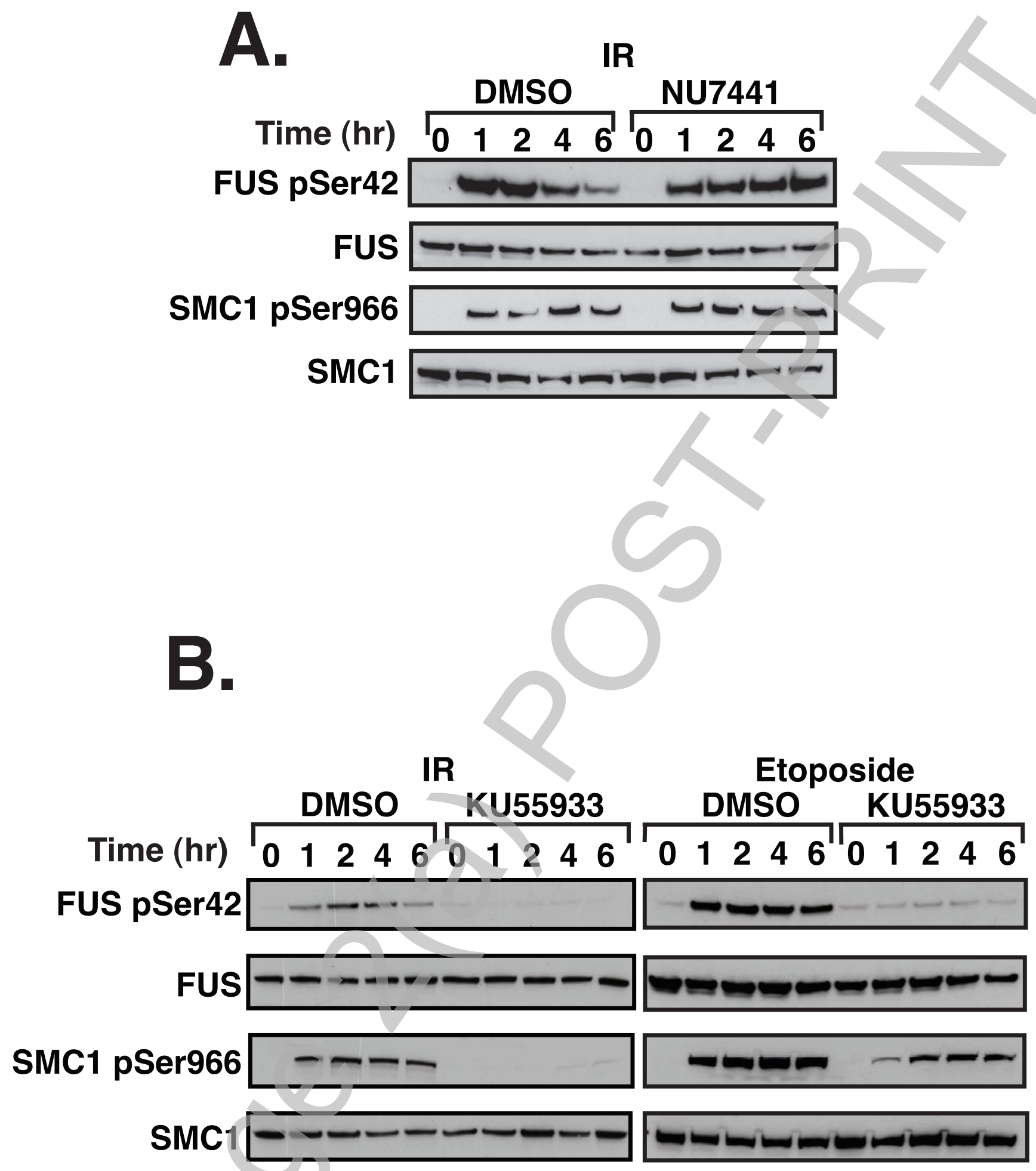